\title{
Analysis and Prospect of Research on Finance Lease in China Based on Co-Word Network
}

\author{
Yuning Chang ${ }^{a}$, Qing Song ${ }^{b}$ \\ Tianjin University of Science \& Technology, Tianjin 300222, China \\ ayuning_chang@sina.com, bsongqing6688@sina.com
}

Keywords: Finance lease, Co-word analysis, Strategic coordinate analysis, Research prospect.

\begin{abstract}
Based on the 2007-2016 core journals and CSSCI journals in the CNKI database as data sources, the research literature on financial leasing for the past ten years was collected; a co-word analysis and a strategic coordinate analysis were conducted, and six recent financial leases were concluded. Hot research areas; analysis of the current research status of these six hot spots, research prospects in this field, hoping to provide inspiration and reference for subsequent research.
\end{abstract}

\section{Introduction}

Leasing is an economic act of borrowing money in kind at a certain cost. A financial lease is a type of leasing, which refers to the lease that transfers most of the risks and rewards related to the ownership of an asset. China's financial leasing companies were established around 1980. Since 2007, the industry scale has begun to show an explosive growth. By the end of 2016, the total number of financial leasing companies in China is about 7,136. According to the data released by the China Leasing Alliance, the contractual balance of China's financial leasing industry increased from 24 billion yuan to approximately 5,330 billion yuan from 2007 to 2016, with an average annual compound growth rate of $82.27 \%$.

With the development of financial leasing industry, its theoretical research has been more than 30 years. The related research papers collected on CNKI have reached more than 20,000 articles. Since 2007, the number of papers published on the subject of financial leasing has been increasing year after year. Especially in the context of "The Belt and Road Initiative" and "Made in China 2025" national strategy, financial leasing has become a research hotspot for many scholars.

In order to systematically analyze the hot spots of financial leasing research, and at the same time put forward research ideas in this field, this paper has collected the research literature on financial leasing from 2007 to 2016 in the past ten years and studied them with co-word analysis. Co-word analysis essentially belongs to content analysis and is widely used in various research fields at home and abroad. The principle is to analyze the keywords appearing in the same paper, and then determine the research position and development status of the research field represented by the keyword in the scope of the subject. This paper takes financial leasing as the research subject, analyzes the keywords in the relevant papers of the research topic, determines the high-frequency keywords according to the statistical results, analyzes the relationship between the keywords, and concludes the research hotspot of financial leasing. The field, and comment on it, finally combined with the analysis of strategic coordinates, carried out research prospects, hoping to provide inspiration and reference for follow-up related research.

\section{Data Sources and Preprocessing}

\subsection{Data Sources.}

In order to guarantee the completeness of data collection and the authoritativeness and representativeness of the selected documents, this paper searches for titles in the titles of CNKI core journals and CSSCI journals that include "finance lease". The time is set to 2007-2016. A total of 472 
papers were retrieved. Excluding keywords and irrelevant papers, a total of 434 valid papers were obtained.

\subsection{Determine High Frequency Keywords.}

On the basis of the above-mentioned 434 document keywords, through the steps of synonym combining and correcting, we used the data sorting and data perspective functions in Excel to obtain key frequency statistics on China's financial leasing related issues. According to the low-frequency word high-frequency word distinction formula: $T=\left(-1+\sqrt{1+8 I_{1}}\right) / 2$ (where $\mathrm{T}$ is the high-frequency word threshold, I1 is the number of words whose word frequency is 1 ) to calculate the high-frequency word threshold. The 26 keywords whose last selected word frequency is greater than or equal to 5 are high-frequency keywords, as shown in Table 1.

Table 1. High-frequency keywords frequency

\begin{tabular}{|c|c|c|c|c|c|}
\hline Key words & $\begin{array}{c}\text { Word } \\
\text { frequency }\end{array}$ & Key words & $\begin{array}{c}\text { Word } \\
\text { frequency }\end{array}$ & Key words & $\begin{array}{c}\text { Word } \\
\text { frequency }\end{array}$ \\
\hline Finance lease & 385 & Tax burden & 17 & Countermeasure & 7 \\
\hline BT TO VAT & 42 & Operation lease & 16 & Enterprise accounting & 7 \\
\hline Risk management & 27 & $\begin{array}{l}\text { Ship financing } \\
\text { lease }\end{array}$ & 14 & Financial charges & 7 \\
\hline $\begin{array}{l}\text { Medium-sized and } \\
\text { small enterprises }\end{array}$ & 25 & Financial lease & 13 & $\begin{array}{l}\text { Interest rate implicit in } \\
\text { lease }\end{array}$ & 7 \\
\hline Lessor & 23 & Initial direct cost & 12 & Lease criteria & 7 \\
\hline Tax policy & 21 & Risk & 9 & Hire purchase & 6 \\
\hline leaseback & 19 & $\begin{array}{l}\text { Accounting } \\
\text { treatment }\end{array}$ & 9 & $\begin{array}{l}\text { Financial leasing in the } \\
\text { free trade area }\end{array}$ & 6 \\
\hline $\begin{array}{l}\text { Unguaranteed } \\
\text { residual value }\end{array}$ & 18 & $\begin{array}{l}\text { Unrealized } \\
\text { financing } \\
\text { income }\end{array}$ & 9 & $\begin{array}{l}\text { Construction } \\
\text { machinery }\end{array}$ & 5 \\
\hline lessee & 18 & $\begin{array}{l}\text { Project finance } \\
\text { lease }\end{array}$ & 9 & & \\
\hline
\end{tabular}

\subsection{Building a Co-Word Matrix.}

Table 1 shows the high-frequency keywords of China's financial leasing research. Among them, the one with the highest frequency of occurrence is "finance lease". Since this article deals with the issues related to financial leasing, this keyword is meaningless in this study and should be deleted when performing co-word analysis. A single keyword is not sufficient to show the overall picture of the financial leasing problem in China. The comprehensive analysis of the links between keywords in related papers can reflect the current status of the research topic. This article uses Excel to achieve the co-occurrence of keywords, and statistics of the frequency of 25 high-frequency keywords co-occurrence, and finally constitute a $25 \times 25$-co-word matrix.

Because the size of the keyword itself affects the calculation of co-occurrence frequency, in order to better express the correlation between the keywords, this paper uses Ochiai correlation coefficient to adjust the above co-word matrix, and then convert it into a correlation matrix. Correlation matrix is the data base for factor analysis and cluster analysis. According to the logical relation between the correlation matrix and the dissimilarity matrix, the dissimilarity matrix is calculated. Dissimilarity matrix is the data basis for strategic coordinate analysis.

\section{Financial Leasing Research Hotspot Determination Process}

\subsection{Using Factor Analysis to Determine the Minimum Number of Keywords.}

Factor analysis is used to determine the minimum number of factors to be extracted, so that a large number of original data can be selected to contain representative factors for subsequent analysis. This article uses SPSS19.0 to achieve multivariate statistical analysis, the above-mentioned correlation matrix data into software for factor analysis. According to the data mining theory, it can be seen that when the common factor extraction number is six, the common factor cumulative variance 
contribution rate can be more than $60 \%$. Therefore, the minimum number of clusters selected for keyword analysis is six.

\subsection{Using Cluster Analysis to Determine Specific Categories of Keywords.}

The above factor analysis provides theoretical support for the next cluster analysis, so the cluster analysis must ensure that the number of categories is greater than or equal to six. Using system clustering analysis, the cluster analysis tree shown in Figure 1 was obtained.

Tree diagram with Ward joins

\begin{tabular}{|c|}
\hline Initialdirect cost \\
\hline Unrealized financing income \\
\hline Lessee \\
\hline Lessor \\
\hline Accounting treatment \\
\hline Unguaranteed residual value \\
\hline Lease criteria \\
\hline Enterprise accounting \\
\hline Financial charges \\
\hline Interest rate implicit in lease \\
\hline Ship financing lease \\
\hline Risk \\
\hline Countermeasure \\
\hline Risk management \\
\hline Medium sized and small enterprises \\
\hline Financial leasing in the free trade area \\
\hline Tax burden \\
\hline BT TO VAT \\
\hline Tax policy \\
\hline Construction machinery \\
\hline Leaseback \\
\hline Financial lease \\
\hline Operation lease \\
\hline Hire purchase \\
\hline
\end{tabular}

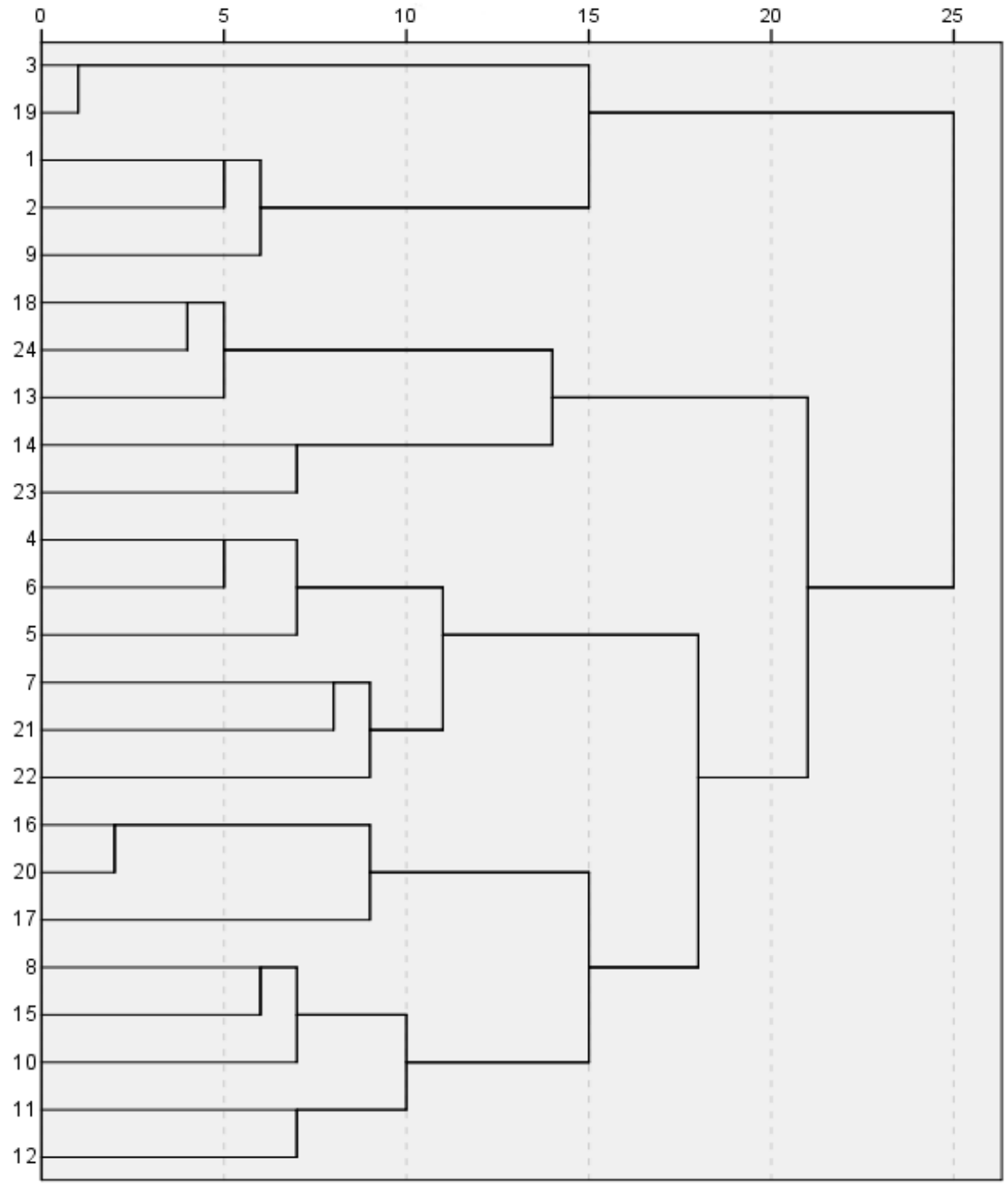

Fig 1. High frequency keyword cluster analysis tree diagram

Clustering closely related keyword nodes into sub-groups. By analyzing the semantic relationships of various keywords, 25 keywords can be generated into 6 sub-groups. These six types of issues are the focus of financial leasing research. The first type (K1) is the confirmation and measurement of the lessor's initial direct costs and unrealized financing income. The second type (K2) is the financial accounting treatment of financial leasing. The third type (K3) is the confirmation of financing expenses. The fourth type (K4) is the risk faced by the financial leasing industry. The fifth type (K5) is a taxation issue for financial leasing. The sixth type (K6) is for different rental options.

\subsection{Using Social Network Analysis to Test the Rationality of Keyword Clustering.}

In order to further verify the above conclusions, we use social network analysis to visualize the hot issues of financial leasing research, and then test the rationality of the above clustering. A $26 \times 26$ correlation matrix containing the keyword "finance lease" was imported in Ucinet 6.0, and a network diagram was drawn using Netdraw. 
In Figure 2, the keyword "finance lease" is at the center of the entire network diagram. The keywords surrounding the financial lease cover the above six sub-groups. This confirms the rationality of clustering analysis to classify 25 high-frequency keywords into 6 categories.

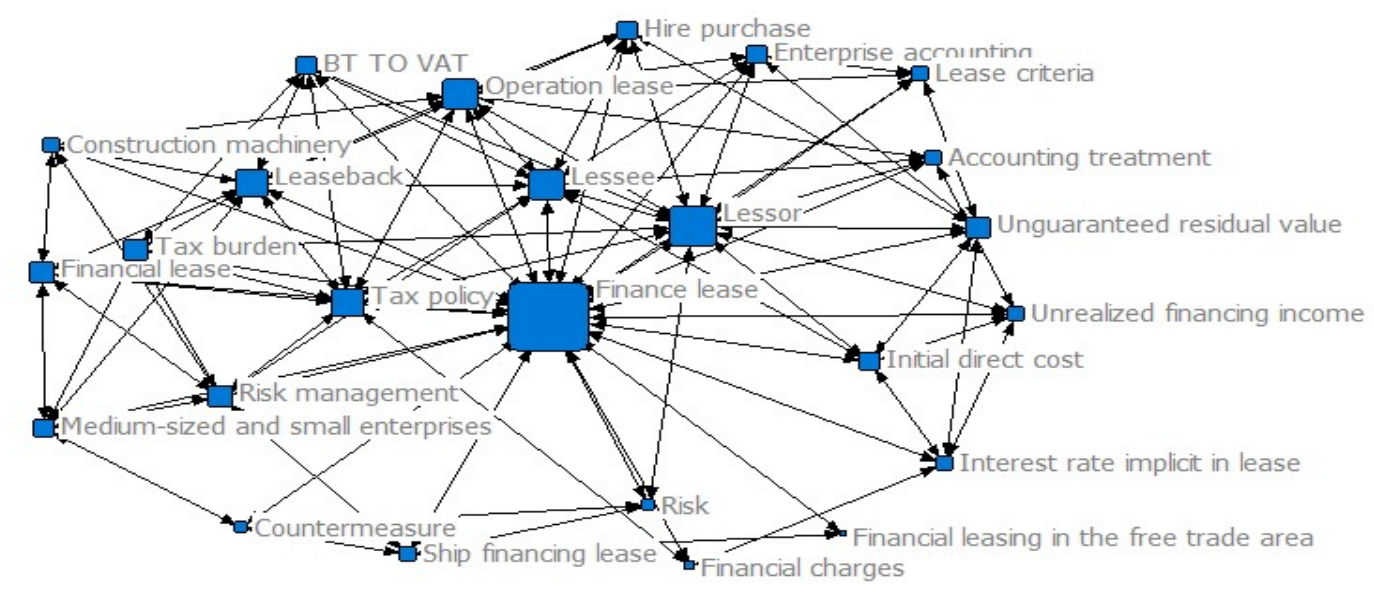

Fig 2. Keywords social network analysis

\section{The Research Hotspot Analysis of Financing Lease}

Based on the above statistical analysis, the research hotspot of China's financial leasing issue can be summarized into six aspects. Based on the current situation of the development of the discipline, the following six brief research hotspots for financial leasing are briefly analyzed.

(1) The lessor's initial direct costs and the recognition and measurement of unrealized financing income. The related paper points out that you cannot use the same method to deal with both. Zhang Zihui (2009) analyzes whether the lessee is willing to bear the initial direct cost: When the lessee is willing to pay, the initial direct costs should be capitalized and should be included in the calculation of unrealized financing income. Conversely, they should be expensed without taking into account the calculation of the unrealized financing income. At the same time, some scholars have also explored the relevant provisions of the "Accounting standards for enterprises" guidelines for dealing with both.

(2) Accounting and handling of financial leases. Some scholars have made a clear understanding of the relevant contents of the financial leasing accounting treatment from the perspective of the lessee and the lessor. Some scholars also analyzed the impact of changes in the policy environment on the accounting treatment of financial leasing. Huang Shiwei (2016) compares and analyzes the differences in accounting and accounting treatment of finance leases before and after the "BT TO VAT" and discusses the impact of this policy change on corporate accounting and taxation.

(3) Confirmation of financing costs. The research on the confirmation of financing costs in the relevant literature mainly focuses on the unrecognized financing expenses. There are disputes on the accounting treatment regarding whether they should be capitalized or expensed in the theoretical community. Huang Hao, Wang Lin and Wang Zheng (2007) conducted comparative analysis of the two methods of accounting for unrecognized financing fees and concluded that capitalization is the most reasonable. Because it is formed by the leasing of fixed assets, although it is a form of cost, capitalization can better reflect the principle that the substance is greater than the form. Scholars at this stage tend to capitalize unrecognized financing costs.

(4) The risks faced by the financial leasing industry. Financial leasing is an emerging financial industry, and financial risks have always been involved. Li Hui (2017) elaborated the causes of risks from the perspective of financing risks, analyzed the relationship between leasing and financing risks, and briefly described preventive measures. Through learning from successful foreign risk control experience, we hope to provide guidance and suggestions on the risk control of China's financial leasing business, and thus promote the flourishing development of the financing market.

(5) The taxation of financial leasing. The tax issues covered by the finance lease business include stamp duty, deed tax, corporate income tax, business tax, and value added tax. In May 2016, the 
financial leasing industry changed from the original business tax to the value-added tax, which had a huge impact on the accounting treatment of the industry. Zhao Enbo (2016) mainly conducts research on four aspects of initial business confirmation, differential taxation, daily operation and management expenses, and consulting service income, and proposes that tax internal management and risk control should be strengthened, tax planning work should be done well, and financial risks should be avoided.

(6) Different rental options. The cost of different leasing methods varies greatly. To reduce costs, many researchers have been working hard to innovate on financial leasing methods. Wu Geshan (2012) comprehensively analyzed the financing leasing problem of small and medium-sized enterprises in China and systematically designed the financing leasing method. This innovative measure has given strong support to the rapid development of its financial leasing business.

\section{Research Perspective Based on Strategic Coordinate Analysis}

Strategic coordinates are two-dimensional coordinates, with the horizontal and vertical axes representing centripetal degrees and densities. Concentricity is the measure of the degree of association between a cluster keyword and the rest of the cluster keywords, indicating the relationship between a discipline and other disciplines. The greater the degree of compassion, the more dominant the subject is in this research system. Density is the measure of the degree of connection between keywords in a group and represents the ability of the category to develop itself. The greater the density, the deeper the internal research in this discipline.

In order to further understand the development of various research themes of financial leasing, a strategic coordinate analysis was conducted on the above keywords. Calculate the centripetal degree and density of each sub-clustering group studied in the financial leasing literature and draw the strategic coordinate diagrams of the six major groups. See Figure 3 for details.

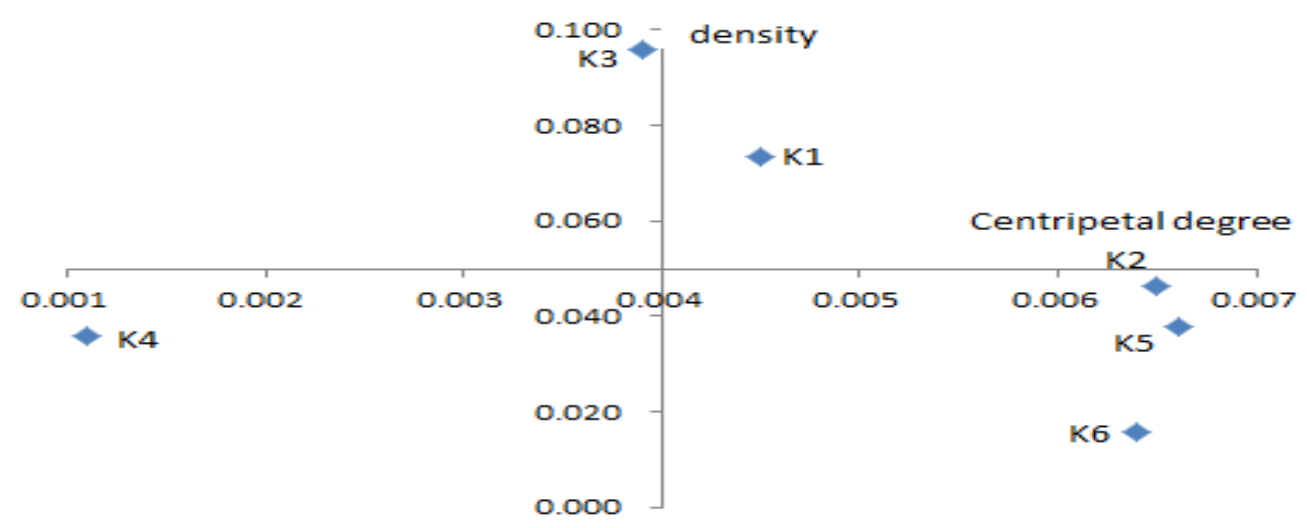

Fig 3. Thematic group strategy map

Based on the above analysis, this paper proposes the following research ideas.

(1) Improve research on financial leasing business regulations in the "Accounting Standards for Enterprises". The degree of concentricity and density of K1 clusters are at the middle and upper levels, indicating that the subject of the study is at a mature stage. However, many scholars have questioned the relevant provisions of the initial direct billing accounting treatment of the financial leasing business in the "Accounting Standards for Enterprises", indicating that the accounting standards for the leased part need to be further explored. Therefore, relevant researchers can work hard to provide more suggestions for the revision of the "Accounting Standards for Enterprises ".

(2) Explore the research on accounting and accounting treatment of financial leasing under different perspectives. The highest degree of concentricity of K2 clusters indicates that the research topic is of a higher status and is closely related to the research of other clusters. However, the study density is at a medium level, indicating that this group's own research needs to be further excavated. Under the background of "BT TO VAT" the analysis and corresponding changes in policy 
environment have brought about the impact of the financial leasing industry's accounting work should be the focus of relevant scholars.

(3) Research on broadening financing costs. The density of K3 clusters is the largest, but the centrality of the K3 clusters indicates that it is not closely related to other research groups. If the linkage with other groups is strengthened, new breakthroughs may be made in the study of financing costs.

(4) Strengthen research on financial lease risk control in specific industries. The K4 group has the lowest centripetal degree and the density is at a medium level, indicating that it is not closely related to other research groups and the connection within its own group is not close enough. With the gradual growth of the financial leasing industry, this research topic is a potentially emerging and important research topic. If the study is carried out in conjunction with free-rent financing leases or ship finance leases, it may form another research hotspot in this field.

(5) Refine the research on taxation of financial leasing. The higher degree of concentricity and density of the $\mathrm{K} 5$ clusters indicate that taxation is an important part of the financial leasing business. However, the research structure of this group is loose and needs further study. With the expansion of financial leasing business, relevant tax policies are continuously refined, so it is possible to discuss the impact of tax policy changes and analyze the specific taxes of a business.

(6) Innovate the combination and development mode of financial leasing. The degree of concentricity and density of K6 clusters is relatively low. Considering this category has more keywords, it indicates that the field needs to further refine key issues and agglomerate the core research directions. Enterprises should combine the latest policy orientation and the company's own capital situation to choose the right financing combination and use internet technology to innovate the development mode of financial leasing.

\section{Summary}

This paper takes "finance lease" as its research theme, and based on the key words in relevant papers, it conducts multivariate statistical analysis, social network analysis, and strategic coordinate analysis, and summarizes the six research groups of China's financial leasing issue. Major groups covered the legal, accounting, taxation, and risk aspects of the finance lease industry, and analyzed the research status of the six major groups. At the same time, it is pointed out that the issue of revising the "Accounting Standards for Enterprises", the impact of policy changes on the accounting treatment of the financial leasing industry, the research on the risks associated with the financial leasing in the Free Trade Zone, and the taxation of finance leases will be the focus of future research. It is hoped that this will provide a reference for the follow-up study of China's financial leasing issue.

\section{References}

[1]. China Lease Alliance. 2016 China Financial Leasing Industry Development Report. Nankai University Press, 2017.

[2]. Shuai Xiaolin. Financing difficulties and Countermeasures of private small and medium sized enterprises. Contemporary economic management. Vol. 13 (2016) No. 10, p. 79-83.

[3]. Liu Jia. Analysing the Advantages and Confusions of Enterprises Adopting Financial Leasing Methods at Present Stage. Financial economy. Vol. 8 (2010), p. 133-134.

[4]. Xiao Wei. The Financial Impact and Countermeasures of the Full-scale "Budget Improvement" on Leasing Enterprises. China International Finance. Vol. 16 (2017) No. 7, p. 31-33.

[5]. Sun Yongjie. Financing difficulties and Countermeasures of private small and medium sized enterprises. Contemporary economic management. Vol. 29 (2017) No. 14, p. 117-120.

[6]. Zong Wenjuan. Risk Analysis and Response of Financing Leasing Industry. Financial economy. Vol. 38 (2016) No. 20, p. 90-91. 